\title{
KINERJA REKSA DANA PASAR UANG DENGAN METODE SHARPE, TREYNOR DAN JENSEN PADA BURSA EFEK INDONESIA (BEI) - PERIODE 2013 - 2017
}

\author{
Budhi Suparningsih *) \\ *) Dosen Program Studi Manajemen FE UNKRIS \\ Alamat: Kampus UNKRIS, Jatiwaringin Jakarta Timur \\ Email : budhiunkris@gmail.com
}

\begin{abstract}
This study aims to determine the performance of money market mutual funds using the Sharpe, Treynor and Jensen methods for 5 years from 2013 to 2017. This research uses qualitative quantitative design. The selected money market mutual fund products are 5 aggressive money market mutual fund products, where the asset allocation is money assets. Data analysis method uses Sharpe, Treynor and Jensen methods. In general, the performance of money market mutual funds based on the Sharpe, Treynor and Jensen methods has fluctuated. The higher the value of Sharpe, Treynor and Jensen, the better the performance of the Money Market mutual fund, because it can provide actual return that is higher than the expected return so as to minimize the individual risk that it bears. Mutual funds with Sharpe and Jensen approaches, the best performance of money market mutual funds is PT Bahana Dana Likuid. Whereas according to Treynor's approach the best is Danamas Rupiah Plus because for five years it gives a positive value. This shows that it is useful to provide information to investors who want to invest in Money Market Mutual Funds, because it results in a higher return on risk-free investment.
\end{abstract}

Keywords: Method Sharpe, Treynor and Jensen

\section{PENDAHULUAN}

Untuk mendukung jalannya suatu investasi, maka dibentuklah suatu lembaga yang menyediakan sarana perdagangan efek yaitu Bursa Efek Indonesia (BEI). Bursa Efek Indonesia adalah pihak yang menyelenggarakan dan menyediakan sistem dan atau sarana untuk mempertemukan penawaran jual dan beli efek pihak-pihak lain dengan tujan memperdagangkan efek diantara mereka (UU Pasar Modal No.8 Tahun 1995). Salah satu instrumen yang diperdagangkan di Bursa Efek Indonesia (BEI) adalah Reksa Dana.

Para investor pemula atau investor yang bimbang atau galau dalam memilih investasinya, mereka cenderung memilih berinvestasi pada reksa dana campuran (kompas.com). Reksa dana campuran memiliki kebijakan yang sangat fleksibel dan relatif lebih aman. Karena reksa dana jenis ini memiliki alokasi aset yang sesuai dengan risiko profil dan tujuan investasi bagi investor. Reksa dana campuran merupakan jenis reksa dana yang memiliki tingkat risiko yang moderat karena dananya ditempatkan pada instrumen ekuitas dan pasar uang. Dengan melakukan investasi pada reksa dana campuran, risiko investasi yang dimiliki dapat tersebar. Apabila satu efek pada investasi tersebut mengalami kerugian, investor masih bisa mendapatkan keuntungan dari efek yang lainnya.

Kinerja reksa dana merupakan tolak ukur perkembangan suatu reksa dana. Kinerja reksa dana memiliki peran penting bagi investor dalam membuat suatu keputusan dalam melakukan investasi tersebut dengan cara melihat kinerja reksa dana yang terjadi pada masa 
lalu serta membandingkannya apakah reksa dana tersebut memberikan keuntungan yang optimal.

Berdasarkan uraian diatas, maka kajian ini menjadi penting untuk diteliti dimana kinerja reksa dana sangat berperan penting dalam pengambilan keputusan bagi para investor, khususnya reksa dana pasar uang.

\section{LANDASAN TEORI}

Reksa dana berasal dari dua kata, yaitu 'reksa' yang berarti 'jaga' atau 'pelihara' dan kata 'dana' yang berarti (kumpulan) uang. Sehingga reksa dana dapat disimpulkan sebagai 'kumpulan uang yang dipelihara'. Di Amerika, reksa dana lebih dikenal dengan istilah mutual fund yang berarti dana bersama, sedangkan di Inggris reksa dana dikenal dengan istilah unit trust yang artinya unit kepercayaan. Di jepang, reksa dana juga cukup populer dengan sebutan investment fund yang artinya pengelolaan dana yang dilakukan untuk investasi dengan menganut asas kepercayaan. Reksa dana merupakan dana bersama yang dikelola oleh perusahaan investasi dengan cara mengumpulkan uang dari pemegang saham yang selanjutnya akan diinvestasikan ke dalam berbagai portofolio seperti saham, obligasi, opsi, komoditas, atau sekuritas pasar uang. Menurut Wijaya (2014), reksa dana adalah wadah dana pola pengelolaan dana/modal bagi sekumpulan investor untuk berinvestasi dalam instrumeninstrumen investasi yang tersedia di pasar dengan cara membeli unit penyertaan reksa dana. "Reksa dana dapat diartikan sebagai jumlah dana yang dihimpun dari masyarakat untuk dikelola oleh manajer investasi dalam bentuk portofolio surat berharga seperti saham, obligasi, instrumen pasar uang, deposito, uang kas, atau kombinasi dari instrumen-instrumen diatas", (Iman, 2008).
Reksa dana merupakan suatu pilihan bagi masyarakat terutama pemodal, khususnya pemodal kecil dan pemodal yang tidak memiliki waktu serta keahlian dalam menghitung risiko atas investasi mereka. Reksa dana dipersiapkan sebagai media yang berguna untuk menghimpun dana dari masyarakat yang memiliki modal dan memiliki tujuan untuk melakukan investasi, akan tetapi hanya memiliki waktu, pengetahuan dan keahlian yang terbatas.

Berdasarkan Undang-Undang Pasar Modal No. 8 tahun 1995, pasal 1 ayat 27 diartikan bahwa "reksa dana adalah wadah yang dipergunakan untuk menghimpun dana dari masyarakat investor untuk selanjutnya diinvestasikan dalam portofolio efek oleh manajer investasi." Portofolio efek merupakan gabungan (perpaduan) sekuritas, surat berharga atau efek, dan instrumen yang dikelola. Terdapat tiga hal yang terkait dengan definisi tersebut, yaitu: 1) Adanya dana dari masyarakat investor; 2) Dana tersebut diinvestasikan ke dalam portofolio efek; 3) Dana tersebut dikelola oleh manajer investasi

Dengan adanya reksa dana, para investor tidak perlu membeli berbagai alat investasi, cukup hanya memiliki surat berharga yang diterbitkan oleh pihak reksa dana. Untuk memaksimalkan keuntungan, pihak reksa dana melakukan pertimbangan-pertimbangan khusus dalam melakukan aktivitas investasi pada berbagai macam surat berharga agar hasilnya lebih optimal.

Reksa dana akan mempublikasikan berbagai saham yang akan dijual kepada investor agar para investor tertark untuk bergabung dalam investasi tersebut. Apabila dana dari investor teah terkumpul, maka dana tersebut siap untuk diinvestasikan dalam diversifikasi portofolio yang dianggap menguntungkan. Kemudian keuntungan yang diperoleh akan dibagikan kembali kepada para investor. 
Diversivikasi dalam pemilihan portofolio efek sangatlah penting agar dapat meminimalkan risiko yang dapat terjadi dikemudian hari. Diversifikasi adalah metode yang digunakan dalam membangun portofolio dengan cara memasukkan beberapa instrumen investasi yang berbeda-beda.

\section{Klasifikasi Reksa Dana}

Reksa dana dapat diklasifikasikan dari beberapa sudut pandang. Diantaranya : 1) Berdasarkan bentuk; Dilihat berdasarkan bentuknya, reksa dana dapat dibagi menjadi : a). Reksa Dana berbentuk perseroan (Corporate Type); Reksa dana berbentuk perseroan adalah perusahaan penerbit reksa dana yang aktivitas usahanya menghimpun dana dengan menjual saham, dan selanjutnya akan menginvestasikan dana dari hasil penjualan tersebut kedalam berbagai jenis efek yang diperdagangkan baik di pasar modal maupun pasar uang. Reksa dana bentuk perseroan ini dapat dibedakan lagi berdasarkan sifatnya yaitu reksa dana perseroan tertutup dan reksa dana perseroan terbuka. Ciri-ciri yang dimiliki bentuk reksa dana ini antara lain Bentuk hukum dari reksa dana ini adalah Perseroan Terbatas (PT); Kekayaan reksa dana dikelola berdasarkan kontrak antara direksi perusahaan dengan manajer investasi yang dipilih; Kekayaan reksa dana disimpan berdasarkan kontrak antara manajer investasi dengan Bank Kustodian; Reksa Dana berbentuk kontrak investasi kolektif (Contractual Type). b). Reksa dana berbentuk kontrak investasi kolektif; Reksa dana ini merupakan kontrak antara manajer investasi dan Bank Kustodian yang mengikat pemegang Unit Penyertaan (UP), dimana manajer investasi diberi wewenang untuk mengelola portofolio investasi kolektif dan Bank Kustodian juga diberi wewenang dalam melaksanakan penitipan kolektif. Reksa dana bentuk ini lebih populer jika dibandingkan dengan reksa dana yang berbentuk perseroan dan jumlahnya juga makin banyak seiring dengan kepopulerannya. Reksa dana jenis ini juga memiliki ciri-ciri, diantaranya: Bentuk hukum reksa dana ini adalah kontrak investasi kolektif; Reksa dana dikelola oleh manajer investasi berdasarkan kontrak; Kekayaan investasi kolektif disimpan oleh Bank Kustodian berdasarkan kontrak. 2) Berdasarkan sifat; Berdasarkan sifatnya, reksa dana dapat dibedakan menjadi : a). Reksa dana bersifat tertutup (Closed-End Fund); Jenis reksa dana ini tidak dapat membeli kembali saham-saham yang telah dijual kepada investor. Pemegang saham tidak dapat menjual kembali sahamnya kepada manajer investasi. Investor yang berniat menjual sahamnya harus dilakukan melalui bursa efek tempat reksa dana tersebut diterbitkan. Penentuan harga di bursa tergantung pada permintaan dan penawaran yang terjadi. b). Reksa dana bersifat terbuka (Open-End Fund); Pada reksa dana ini menawarkan dan membeli kembali saham-sahamnya dari investor sampai sejumlah modal yang sudah dikeluarkan. Para investor dapat menjual kembali saham /unit penyertaanya setiap saat kapan saja investor tersebut ingin menjualnya sesuai dengan Nilai Aktiva Bersih (NAB) per saham atau per unit pada saat tersebut. 3) Berdasarkan Portofolio Investasi; Berdasarkan portofolio investasinya, reksa dana dapat dibedakan menjadi: a). Reksa Dana Pasar Uang (Money Market Funds); Reksa dana yang mengalokasikan seluruh asetnya pada instrumen pasar uang. Instrumen pasar uang adalah efek utang yang jangka waktunya kurang dari satu tahun, misalnya Sertifikat bank Indonesia (SBI), deposito, atau obligasi yang memiliki jangka waktu kurang dari satu tahun. Reksa dana pasar uang memiliki risiko paling kecil diantara reksa dana lainnya. b). Reksa Dana Pendapatan Tetap (Fixed Income Funds); Reksa dana yang 
mengalokasikan seluruh asetnya pada efek utang, umumnya obligasi. Reksa dana pendapatan tetap memiliki risiko sedikit lebih besar dari reksa dana pasar uang. Karena $80 \%$ atau lebih dana yang dikelola diwajibkan dalam bentuk portofoli utang, baik utang obligasi swasta maupun pemerintah dalam jangka waktu yang lebih dari satu tahun. c). Reksa Dana Saham (Equity Funds); Reksa dana yang mengalokasikan portofolionya $80 \%$ atau lebih di dalam surat berharga yaitu saham. Sampai saat ini manajer investasi yang mengelola reksa dana saham hanya diperbolehkan membeli surat berharga yang listing pada Bursa Efek Indonesia. Reksa dana saham memiliki risiko paling besar diantara reksa dana lainnya, karena fluktuasi harga saham yang dinamis. d). Reksa Dana Campuran (Discretionary Funds); Reksa dana yang mengalokasikan dananya pada efek ekuitas (saham) dan efek utang (obligasi dan deposito) dengan komposisi yang tidak termasuk kategori reksa dana pendapatan tetap, reksa dana saham, maupun reksa dana pasar uang. Reksa dana campuran memiliki risiko yang bersifat moderat karena tingkat fleksibelitasnya dalam mengatur alokasi penempatan dana serta pemilihan portofolio. e). Reksa Dana Terproteksi; Reksa dana terproteksi memberikan proteksi terhadap nilai awal investasi pada saat jatuh tempo. Investasi harus dilakukan pada efek hutang yang masuk dalam investment grade dengan peringkat layak investasi oleh manajer investasi. Jatuh tuh tempo efek hutang setidaknya lebih awal dari jatuh tempo reksa dana terproteksi. Reksa dana ini memiliki risiko moderat. f). Reksa Dana Penjamin; Reksa dana penjamin memberiikan penjaminan atas nilai modal beserta hasil investasi yang akan didapatkan saat jatuh tempo. Penjaminan dilakukan oleh bank atau perusahaan asuransi selaku pihak ketiga. Risiko reksa dana ini cenderung lebih kecil. g). Reksa Dana Indeks; Reksa dana indeks memiliki pertumbuhan yang mengikuti indeks yang dijadikan sebagai acuan reksa dana tersebut. Manajer investasi harus melakukan investasi sekurang-kurangnya $80 \%$ dari NAB reksa dana tersebut sekurang-kurangnya $80 \%$ dari efek-efek yang merupakan bagian dari kumpulan efek yang ada dalam indeks tersebut. Reksa dana ini memiliki risiko moderat.

\section{METODE PENELITIAN}

Metode Sharpe, Treynor, dan Jensen merupakan beberapa metode yang dapat digunakan untuk mengukur atau menilai suatu kinerja reksa dana. Para investor dapat menggunakan ketiga metode tersebut untuk melihat kinerja reksa dana karena ketiga metode tersebut memiliki analisis yang berbeda satu sama lain.

\section{HASIL PENELITIAN :}

\section{Hasil Rata-rata Return Bulanan Reksa Dana Pasar Uang}

Untuk menghitung rata-rata bulanan reksa dana Pasar Uang langkah pertama yang dilakukan adalah menghitung return dari Nilai Aktiva Bersih (NAB) dengan rumus sebagai berikut:

$R p=\frac{N A B_{t}-N A B_{t-1}}{N A B_{t-1}}$

Dimana :

$R p=$ Return bulanan reksa dana

$\mathrm{NAB}_{\mathrm{t}}=\mathrm{NAB}$ pada periode pengukuran

$\mathrm{NAB}_{\mathrm{t}-1}=\mathrm{NAB}$ pada periode sebelum pengukuran

Pada perhitungan ini adalah menghitung rata-rata return bulanan Reksa Dana Pasar Uang. Cara menghitungnya adalah dengan cara membagi jumlah akumulasi return selama periode pengamatan dengan jumlah periode pengamatan. Rumus yang digunakan adalah sebagai berikut : 
$\bar{R} p \quad=\frac{\sum R p}{n}$

Dimana:

$\bar{R} p \quad=$ Rata-rata return bulanan Reksa

Dana Pasar uang

$\sum R p=$ Jumlah return bulanan Reksa

Dana Pasar Uang periode tertentu

$\mathrm{n} \quad=$ Jumlah periode perhitungan

\section{Kinerja Reksa Dana Pasar Uang Dengan Metode Sharpe}

Dalam menghitung kinerja reksa dana dengan metode Sharpe adalah dengan menghitung standar deviasi dari masing-masing. Reksa Dana Pasar uang. Pada penelitian ini, perhitungan standar deviasi dihitung menggunakan program dari Microsoft Excel dengan rumus (= stdev) atau dengan rumus manual sebagai berikut:

$$
\sigma \quad=\sqrt{\frac{\sum(x-\mu)^{2}}{n-1}}
$$

Dimana:

$$
\begin{array}{ll}
\sigma & =\text { Standar deviasi } \\
\mathrm{x} & =\text { Nilai data } \\
\mu & =\text { Rata-rata hitung } \\
\mathrm{n} & =\text { Jumlah data }
\end{array}
$$

Tabel 1 : Kinerja Reksa Dana Pasar Uang - Metode Sharpe Periode 2013 sampai dengan tahun 2017

\begin{tabular}{lccccc}
\hline \multicolumn{1}{c}{ PRODUK } & $\mathbf{2 0 1 3}$ & $\mathbf{2 0 1 4}$ & $\mathbf{2 0 1 5}$ & $\mathbf{2 0 1 6}$ & $\mathbf{2 0 1 7}$ \\
\hline Bahana Dana Likuid & $-1.71143 *)$ & $\left.1.78282^{*}\right)$ & $0.02451 *)$ & 1.27686 & $\left.3.90655^{*}\right)$ \\
Danamas Rupiah Plus & -2.74494 & $\left.-4.94845^{* *}\right)$ & $-11.37759 * *)$ & $\left.-3.54991^{* *}\right)$ & $-0.05472 * *)$ \\
Mega Asset Multicash & -2.53800 & 0.05962 & -0.00753 & 0.42352 & 0.42832 \\
MNC Dana Lancar & -2.68227 & -0.26782 & -1.04121 & $2.79786 *)$ & 3.52798 \\
Trim Kas 2 & $-2.88434 * *)$ & -0.16126 & -0.54844 & 0.12804 & 0.79240 \\
\hline AVERAGE & $\mathbf{- 2 . 5 1 2 2 0 * * * )}$ & $\mathbf{- 0 . 7 0 7 0 2 * * * )}$ & $\mathbf{- 2 . 5 9 0 0 5 * * * )}$ & $\mathbf{0 . 2 1 5 2 7 * * * )}$ & $\mathbf{1 . 7 2 0 1 1 * * * )}$ \\
\hline
\end{tabular}

Sumber: Data diolah

Berdasarkan hasil perhitungan kinerja Reksa Dana Pasar Uang dengan metode Sharpe pada tahun 2013, menunjukkan kelima kinerja Reksa Dana Pasar Uang memiliki nilai yang negatif, dengan tingkat risiko terendah adalah reksa dana Bahana Dana Likuid dari manajer investasi PT. Bahana TCW Investment Management dengan nilai sharpe sebesar -1,71143.

Pada tahun 2014, terdapat dua Reksa Dana Pasar Uang dengan kinerja yang positif sedangkan yang lainnya bernilai negatif, dimana kinerja terbaik adalah reksa dana Bahana Dana Likuid dari manajer investasi PT. Bahana TCW Investment Management dengan nilai sharpe sebesar 1,78282.

Pada tahun 2015, terdapat satu Reksa Dana Pasar Uang dengan kinerja yang positif sedangkan yang lainnya bernilai negatif, dimana reksa dana pasar uang dengan kinerja terbaik adalah Bahana Dana Likuid dari manajer investasi PT. Bahana TCW Investment Management dengan nilai sharpe sebesar 0,02451 .

Sedangkan pada tahun 2016, terdapat empat Reksa Dana Pasar Uang dengan kinerja yang positif dan hanya satu yang bernilai negatif, dengan kinerja terbaik adalah reksa dana MNC Dana Lancar dari manajer investasi PT. MNC Asset Management dengan nilai sharpe sebesar 2,79786.

Dan Pada tahun 2017 terdapat empat Reksa Dana Pasar Uang menunjukkan kinerja yang positif dan yang terbaik adalah reksa dana Bahana Dana Likuid dari manajer investasi PT. 
Bahana TCW Investment Management dengan nilai sharpe sebesar 3,90655. Sedangkan yang bernilai negatif hanya satu yaitu Danamas Rupiah Plus.

Reksa dana yang menghasilkan nilai sharpe yang positif menunjukkan bahwa reksa dana tersebut sudah layak dijadikan sebagai alternatif investasi karena mampu menghasilkan return yang lebih besar dibandingkan dengan return investasi bebas risiko. Sebaliknya, Reksa dana yang menghasilkan nilai sharpe yang negatif menunjukkan bahwa reksa dana tersebut belum layak dijadikan sebagai alternatif investasi karena tidak mampu menghasilkan return yang lebih besar dibandingkan dengan return investasi bebas risiko. Semakin besar nilai Sharpe, maka semakin baik pula kinerja suatu reksa dana pasar uang karena memberikan return yang tinggi dari risiko individual yang ditanggungnya.
Reksa dana terbaik menurut metode Sharpe adalah PT Bahana Dana Likuid karena dari tahun 2014 sampai dengan tahun 2017, memiliki nilai Sharpe yang positif.

\section{Kinerja Reksa Dana Pasar Uang Dengan Metode Treynor}

Tahap pertama pada perhitungan kinerja menggunakan pendekatan Treynor adalah dengan menghitung beta dari masing-masing Reksa Dana Campuran sebagai pembagi. Perhitungan beta pada penelitian ini menggunakan rumus sebagai berikut:

$\beta \quad=\frac{\sigma_{i j}}{\sigma_{m^{2}}}$

Dimana:

$\beta \quad=$ Beta portofolio

$\sigma_{\mathrm{ij}} \quad=$ Kovarians antara return pasar dan return portofolio

$\sigma_{\mathrm{m}^{2}} \quad=$ Varians pasar

Tabel 2 : Kinerja Reksa Dana Pasar Uang - Metode Treynor Periode tahun 2013 sampai dengan tahun 2017

\begin{tabular}{lccccc}
\hline \multicolumn{1}{c}{ PRODUK } & $\mathbf{2 0 1 3}$ & $\mathbf{2 0 1 4}$ & $\mathbf{2 0 1 5}$ & $\mathbf{2 0 1 6}$ & $\mathbf{2 0 1 7}$ \\
\hline Bahana Dana Likuid & $-0.19236 *)$ & 0.09826 & 0.18470 & -0.21935 & $\left.-0.26756^{*}\right)$ \\
Danamas Rupiah Plus & 0.63839 & $1.01736 * *)$ & $435.69256 * *)$ & $0.57915 * *)$ & 0.00453 \\
Mega Asset Multicash & 1.94595 & $\left.-0.00333^{*}\right)$ & -0.01106 & $-1.79926 *)$ & $\left.0.04741^{* *}\right)$ \\
MNC Dana Lancar & $5.22853 *)$ & 0.19745 & $\left.-0.32411^{*}\right)$ & 1.16485 & -0.17867 \\
Trim Kas 2 & 0.47174 & 0.01194 & -0.07911 & 0.00850 & -0.07956 \\
\hline AVERAGE & $\mathbf{1 . 6 1 8 4 5} * * *)$ & $\mathbf{0 . 2 6 4 3 4} * *)$ & $\mathbf{8 7 . 0 9 2 6 0 * * * )}$ & $\mathbf{- 0 . 0 5 3 2 2 * * * )}$ & $\mathbf{- 0 . 0 9 4 7 7 * * * )}$ \\
\hline
\end{tabular}

Sumber: Data diolah

Berdasarkan hasil perhitungan kinerja Reksa Dana Pasar Uang dengan metode Treynor pada tahun 2013 hanya satu yang bernilai negatif sedangkan empat Reksa Dana Pasar Uang bernilai positif dan kinerja terbaik adalah reksa dana MNC Dana Lancar dari manajer investasi PT. MNC Asset Management dengan nilai treynor sebesar 5,22853.

Pada tahun 2014, terdapat empat Reksa Dana Pasar Uang dengan kinerja yang positif dan satu yang bernilai negatif, kinerja terbaik adalah reksa dana Danamas Rupiah Plus dari manajer investasi PT. Sinarmas Asset Management dengan nilai treynor sebesar 1,01736.

Pada tahun 2015, terdapat dua Reksa Dana Pasar Uang dengan kinerja positif dan tiga menunjukkan nilai yang negatif, dimana reksa dana pasar uang dengan kinerja terbaik adalah reksa dana Danamas Rupiah Plus dari manajer investasi PT. Sinarmas Asset 
Management dengan nilai treynor sebesar 453,69256.

Sedangkan pada tahun 2016, terdapat tiga Reksa Dana Pasar Uang yang positif dan dua yang bernilai negatif, dimana reksa dana dengan kinerja terbaik adalah reksa dana Danamas Rupiah Plus dari manajer investasi PT. Sinarmas Asset Management dengan nilai treynor sebesar 0,57915 .

Dan Pada tahun 2017 terdapat dua Reksa Dana Pasar Uang menunjukkan kinerja yang positif dan tiga menunjukkan nilai yang negatif, dimana kinerja terbaik adalah reksa dana Mega Asset Multicash dari manajer investasi PT. Mega Asset Management dengan nilai treynor sebesar 0,04741 .

Reksa dana yang menghasilkan nilai treynor yang positif menunjukkan bahwa reksa dana tersebut sudah layak dijadikan sebagai alternatif investasi karena mampu menghasilkan return yang lebih besar dibandingkan dengan return investasi bebas risiko. Sebaliknya, Reksa dana yang menghasilkan nilai treynor yang negatif menunjukkan bahwa reksa dana tersebut belum layak dijadikan sebagai alternatif investasi karena tidak mampu menghasilkan return yang lebih besar dibandingkan dengan return investasi bebas risiko. Semakin besar nilai Treynor, maka semakin baik pula kinerja suatu reksa dana pasar uang karena memberikan return yang tinggi dari risiko individual yang ditanggungnya.

\section{Kinerja Reksa Dana Pasar Uang Dengan Metode Jensen}

Dalam perhitungan metode Jensen, variabel-variabel yang digunakan diantaranya adalah rata-rata return bulanan, rata-rata return investasi bebas risiko, rata-rata return bulanan IHSG, dan beta portofolio. Rumus yang digunakan untuk mengukur kinerja reksa dana dengan metode Jensen adalah sebagai berikut:

$$
\alpha \quad=\left(\bar{R}_{p}-\bar{R} \bar{f}\right)-\beta_{p}\left(\bar{R}_{m}-\bar{R} \bar{f}\right)
$$

Dimana :

$$
\begin{aligned}
& \alpha=\text { Nilai Perpotongan Jensen } \\
& \bar{R}_{p} \quad=\text { Rata-rata return bulanan Reksa } \\
& \text { Dana Campuran } \\
& \bar{R} \bar{f} \quad=\text { Rata-rata returninvestasi bebas } \\
& \text { risiko } \\
& \bar{R}_{m} \quad=\text { Rata-rata return pasar (IHSG) } \\
& \beta_{p} \quad=\text { beta portofolio }
\end{aligned}
$$

Tabel 3 : Kinerja Reksa Dana Pasar Uang - Metode Jensen Tahun 2013 sampai dengan tahun 2017

\begin{tabular}{lccccc}
\hline PRODUK & $\mathbf{2 0 1 3}$ & $\mathbf{2 0 1 4}$ & $\mathbf{2 0 1 5}$ & $\mathbf{2 0 1 6}$ & $\mathbf{2 0 1 7}$ \\
\hline Bahana Dana Likuid & -0.00177 & $\left.0.00089^{*}\right)$ & 0.00001 & 0.00058 & $0.00146 *)$ \\
Danamas Rupiah Plus & -0.00165 & $\left.-0.00205^{* *}\right)$ & $\left.-0.00206^{* *}\right)$ & $-0.00079 * *)$ & $\left.0.00002^{* *}\right)$ \\
Mega Asset Multicash & $\left.-0.00206^{* *}\right)$ & 0.00033 & $0.00001 *)$ & 0.00062 & 0.00085 \\
MNC Dana Lancar & -0.00173 & -0.00073 & -0.00046 & $\left.0.00095^{*}\right)$ & 0.00136 \\
Trim Kas 2 & $-0.00124 *)$ & -0.00004 & -0.00016 & 0.00009 & 0.00134 \\
\hline AVERAGE & $\mathbf{- 0 . 0 0 1 6 9 * * * )}$ & $\mathbf{- 0 . 0 0 0 3 2} * * *)$ & $\mathbf{- 0 . 0 0 0 5 3 * * * )}$ & $\mathbf{0 . 0 0 0 2 9} * * *)$ & $\mathbf{0 . 0 0 1 0 1 * * * )}$ \\
\hline
\end{tabular}

Sumber: Data diolah

\section{Keterangan:}

$\begin{array}{ll}*) & \text { Tertinggi } \\ * *) & \text { Terendah } \\ * * *) & \text { Rata-Rata }\end{array}$


Berdasarkan hasil perhitungan kinerja Reksa Dana Pasar Uang dengan metode Jensen pada tahun 2013 semua kinerja Reksa Dana Pasar Uang bernilai negatif. Dimana kinerja yang terendah risikonya adalah reksa dana Trim Kas 2 dari manajer investasi PT. Trimegah Asset Management dengan nilai jensen sebesar -0,00124.

Pada tahun 2014, terdapat dua Reksa Dana Pasar Uang yang positif dan tiga yang bernilai negatif, dimana kinerja terbaik adalah reksa dana Bahana Dana Likuid dari manajer investasi PT. Bahana TCW Investment Management dengan nilai jensen sebesar 0,00089 .

Pada tahun 2015, terdapat dua yang positif dan tiga yang negatif, dimana kinerja terbaik adalah reksa dana Mega Asset Multicash dari manajer investasi PT. Mega Asset Management dengan nilai jensen sebesar 0,00001.

Sedangkan pada tahun 2016, terdapat empat Reksa Dana Pasar Uang dengan kinerja yang positif dan satu Reksa Dana Pasar Uang yang bernilai negatif, dan kinerja yang terbaik adalah MNC Dana Lancar dari manajer investasi PT. MNC Asset Management dengan nilai jensen sebesar 0,00095 .

Dan Pada tahun 2017 kelima Reksa Dana Pasar Uang semuanya menunjukkan kinerja yang positif, dengan kinerja terbaik adalah reksa dana Bahana Dana Likuid dari manajer investasi PT. Bahana TCW Investment Management dengan nilai jensen sebesar 0,00146 . Hal ini menunjukkan bahwa pada tahun 2017 kondisi pasar uang yang baik sehingga investor mulai memperhatikan untuk melakukan investasi di reksa dana pasar uang,

Reksa dana yang menghasilkan nilai jensen yang positif menunjukkan bahwa reksa dana tersebut sudah layak dijadikan sebagai alternatif investasi karena mampu menghasilkan actual return yang lebih tinggi daripada return yang diharapkan. Sebaliknya, Reksa dana yang menghasilkan nilai jensen yang negatif menunjukkan bahwa reksa dana tersebut belum layak dijadikan sebagai alternatif investasi karena menunjukkan actual return yang lebih rendah daripada expected return. Semakin besar nilai Jensen, maka semakin baik pula kinerja suatu Reksa Dana Pasar Uang karena memberikan actual return yang lebih tinggi dari pada expected return.

\section{KESIMPULAN}

Penelitian ini bertujuan untuk mengetahui kinerja Reksa Dana Pasar uang menggunakan metode Sharpe, Treynor dan Jensen selama 5 tahun periode tahun 2013 sampai dengan tahun 2017. Secara umum, kinerja reksa dana Pasar uang berdasarkan metode Sharpe, Treynor dan Jensen mengalami fluktuatif. Semakin tinggi nilai Sharpe, Treynor dan Jensen maka semakin baik pula kinerja reksa dana Pasar Uang tersebut, karena dapat memberikan actual return yang lebih tinggi dari pada expected return sehingga dapat meminimalisir risiko individual yang ditanggungnya.

Menurut metode Sharpe Reksa dana pasar uang terbaik adalah PT Bahana Dana Likuid karena dari tahun 2014 sampai dengan tahun 2017, memiliki nilai Sharpe yang positif, sehingga layak untuk diinvestasikan.

Menurut metode Treynor Reksa dana pasar uang terbaik adalah Reksa dana Danamas Rupiah Plus karena dari tahun 2013 sampai dengan tahun 2017, rata rata memiliki nilai Treynor yang positif, sehingga sangat layak untuk diinvestasikan.

Menurut metode Jensen Reksa dana pasar uang terbaik adalah PT Bahana Dana likuid dan Mega Assets Multicash karena dari tahun 2014 sampai dengan tahun 2017, memiliki nilai Jensen yang tinggi, dan layak untuk diinvestasikan. 
Reksadana dengan pendekatan Sharpe dan Jensen, kinerja Reksa Dana pasar uang yang terbaik adalah PT Bahana Dana Likuid. Hal ini menunjukkan bahwa berguna untuk memberikan informasi kepada para investor yang ingin melakukan investasi pada Reksa Dana Pasar Uang, karena menghasilkan nilai return yang lebih tinggi dari investasi bebas risiko.

\section{DAFTAR PUSTAKA}

Anoraga, Pandji dan Piji Pakarti. 2008. Pengantar Pasar Modal. Jakarta: Rineka Cipta

Bodie, Zvi, Alex kane dan Alan J. Marcus. 2014. Manajemen Portofolio dan Investasi. Edisi kedua. Jakarta: Salemba Empat

Darmadji, Tjiptono dan Hendry Fakhruddin. 2012. Pasar Modal Indonesia: Pendekatan Tanya Jawab. Jakarta: Salemba Empat

Fakhruddin, Hendy M. 2008. Istilah Pasar Modal A - Z. Jakarta: PT. Elex Media Komputindo

Gumanti, Tatang Ary. 2011. Manajemen Investasi. Edisi Pertama. Jakarta: Mitra Wacana Media

Halim, Abdul. 2014. Analisis Investasi Dan Aplikasinya: Dalam Aset Keuangan Dan Aset Riil. Jakarta: Salemba Empat

Hanggoro, Wisnu Widhi. 2014. "Analisis Kinerja Reksa Dana Saham Yang Tercatat Pada Bursa Efek Indonesia Dengan Metode Sharpe, Treynor dan Jensen". (Skirpsi). Yogyakarta: Fakultas Ekonomi Universitas Islam Negeri Sunan Kalijaga

Hartono, Jogiyanto. 2016. Teori Portofolio dan Analisis Investasi. Edisi Kesepuluh, Yogyakrta: BPFE

Husnan, Suad. 2010. Manajemen Keuangan Teori \& Penerapan Keputusan Jangka Panjang. Edisi Keempat. Yogyakarta: BPFE
Iman, Novie. 2008. Panduan Singkat dan Praktis Memulai Investasi Reksa Dana. Jakarta: PT. Elex Media Komputindo

Manurung, Adler Haymans. 2008. Reksa Dana Investasiku. Edisi Keempat. Jakarta: Kompas Media Nusantara

Martalena dan Maya Malinda. 2011. Pengantar Pasar Modal. Jakarta: Andi Publisher

Merdekawati, Ika. 2015. "Analisis Kinerja Reksa Dana Saham Dengan Metode Sharpe, Treynor, Jensen dan $M^{2}$ Pada Bursa Efek Indonesia”.(Skripsi). Yogyakarta: Fakultas Ekonomi Universitas Islam Negeri Sunan Kalijaga

Pratomo, Eko Putro dan Ubaidillah Nugraha. 2009. Reksa Dana Solusi Perencanaan Investasi Modern. Jakarta: Gramedia Pustaka Utama

Rudiyanto. 2013. Sukses Finansial Dengan Reksa Dana. Jakarta: Kompas Gramedia

Sekaran, Uma. 2011. Metode Penelitian Untuk Bisnis. Jakarta: Salemba Empat

Solkhan, Moh. 2015. "Analisis Perbandingan Kinerja Reksa Dana Saham, Pendapatan Tetap, dan Campuran Dengan Metode Sharpe, Treynor dan Jensen (Studi Pada Reksa Dana Syariah)". (Skripsi). Semarang: Fakultas Ekonomi dan Bisnis Islam Universitas Islam Negeri Walisongo.

Sugiyono. 2013. Metode Penelitian Kuantitatif, Kualitatif dan $R \& D$. Edisi Kedepalan. Bandung: Alfabeta.

Tandelilin, Eduardus. 2010. Portofolio dan Investasi: Teori dan Aplikasi. Yogyakarta: Kanisius

Undang - Undang Pasar Modal No. 8 Tahun 1995 Pasal 1 ayat 27

Warsini, S. 2009. Manajemen Investasi. Edisi Pertama. Jakarta: Semesta Media 
Widiatmodjo, $\quad$ Sawidji. 2015. Pengetahuan Pasar Modal. Edisi Pertama. Jakarta: Elex Media Komputindo

Widjaja, Gunawan dan Almira Prajana Ramaniya. 2009. Reksa Dana dan Peran Serta Tanggung Jawab Manajer Investasi Dalam Pasar Modal. Edisi Kedua. Jakarta: Kencana

Wijaya, Ryan Filbert. 2014. Menjadi Kaya \& Terencana dengan Reksa
Dana. Edisi Ketiga. Jakarta: Elex Media Komputindo

www.bi.go.id

www.finance.yahoo.com

www.kemenperin.go.id

www.kompas.com

www.ojk.go.id

www.pusatdata.kontan.co.id

Zubir, Zalmi. 2012. Portofolio Obligasi. Jakarta: Salemba Empat 